\title{
On the Translation of Chinese Current Political New Words
}

\author{
Jingjing Cui \\ Foreign Language Department, Dezhou University, Dezhou, China \\ Email: nathy1018@163.com
}

\begin{abstract}
The continuous emergences of new words as well as the gradual disappearances of old words are the law of the development of language and vocabulary. Along with the development and progress of Chinese society, there are large numbers of new words emerged in our daily lives. The quality of the Chinese new words' translations, especially those new words related to the nation's current politics and economy, directly affects China's foreign political, economical and cultural communications. Therefore, it is of vital significance to make researches on the translations of the current political new words, so as to strengthen the Sino-foreign exchanges and cooperation in various aspects. This paper starts from some elementary translation theories, combines with China's current situations, and tries to find some proper basic principles and specific methods to translate Chinese new words.
\end{abstract}

Index Terms - current political new words, problem, strategy

\section{INTRODUCTION}

For the past three decades of reform and opening up, with the overall development of Chinese society, there emerged a large number of new things and phenomena. All kinds of new words have sprung up, the core of which are the new words in terms of current affairs. The translation of the current political new words is a mirror between our country and the international society, by which our country's fundamental situations and development conditions can be fully understood by the outside world. Good translations can promote the understandings of foreigners about China, and convey an open and progressive national image to the whole world, whereas not ideal translations will affect the international communications, even undermine our country's international image. Therefore, perfect translations of current political new words can enable this mirror to play a good role, so as to better promote the communications and cooperation between China and the other countries.

Therefore, in order to improve the overall quality of the English translations of the current political new words, translators should make further researches on both theories and practices of the translations. Enhance our senses of responsibilities, strengthen our studies, pay more attention to the current political knowledge and heighten our capabilities of translating Chinese current political new words.

\section{LITERATURE REVIEW}

Regarding the definition of the current political new words, it is still a little bit confusing. Classified according to their political origins, this kind of glossary includes current national significant events, political situations as well as major policies and aspects involving economy and cultures. People learn current affairs by the channels of television, newspapers and network, through which we can understand the country's major policies. Translators should pay attention to the point that when translating general cultural words, we should take China's cultural structures and historical backgrounds into consideration. And if mistranslations occurred in the translations of the current political words, the direct consequence is the foreigners' misunderstandings to our country's policies, thus becoming their laugh stocks or unnecessary troubles. With regard to the national influences, the impacts are more significant; what is more, these words may be used by the anti-Chinese forces in the international communications and become their weapons to attack China. Therefore, we should consider deeply in the translating process. There are two characteristics of Chinese political new words, i.e. gradualness and Chinese elements.

First of all, the key of the current political new words lies in "freshness", namely gradualness. In some significant conferences or important situations, the country leaders will formulate some new policies according to the concrete conditions, followed by large numbers of new words emitting like mushrooms after rain. For example, the expression of "harmonious society" comes from the concept of "building a harmonious socialist society". These terms appear repeatedly on major media, becoming the focus of the country and the people, thus making extraordinary effects. The emergence of these new words is a reflection of the country's major policies at a certain stage, such as "seize the chance and develop ourselves".

Secondly, the current political new words have rich Chinese elements. The Chinese culture is broad and profound. For instance, more than two thousand years ago, Chinese thinker Confucius proposed a political ideal “大同世界”, 
namely "utopia" in the western world, which is precisely one kind of yearning for a harmonious society. The statement of "harmonious society" not only manifests the national development targets, but also contains essence of Chinese culture. When we translate these glossaries, we should be accurate and manifest their characteristics as much as possible.

English as an international lingua franca in the political, economic, trade, cultural and other spheres have been widely used. Thus, with the rest of the world in China's external political and economic propaganda, we also bound to the use of English expressions of political affairs with Chinese characteristics, terminology. Because in any English dictionary on the impossible to find a direct correspondence we use expressions, so we need to grasp the English language used at the same time, creating a Chinese-English expression. As we all know, "Three Represents"; "four cardinal principles"; "the Four Cardinal Principles"; "keep pace with the times"; and "well-off society": build a well-of society in an all-round way, and so on expressions are recognized by the international community and accepted by Chinese English expression. Thus, when we translate the current political terminology, you need to pay attention to two aspects: on the one hand, to avoid the Chinese taste being too heavy and does not correspond with the English expressions in English, that is, "Chinglish"; On the other hand, translators should thoroughly understand the inner meaning of political terms, avoiding the wrong translation and mistranslation, to end political ambiguity. Political terms and phrases often have a strong policy, therefore, the process of translation can not arbitrarily increase, by which the language and the use of the word. Therefore, it is a challenge for translators. Politics vocabulary according to their different content, different uses can take several different methods of processing and translation.

\section{Problems of Translating Chinese New Words}

\section{A. Difficulties in Translating Current Political New Words}

As far as the present situation of translating Chinese current political new words is concerned, the overall level is not high. The characteristic of "New" has also become the most difficult part in the translating process. Because of the "new", most words have no precedents to be possible to look up, so that the translators are unable to integrate from the general comprehensive Chinese-English dictionaries to obtain fixed answers. It is also because the "new" makes the compilation of new dictionaries quite troublesome, and often couldn't catch up with the birth of new words. Therefore, the promotion of the new words is quite difficult, the translators could only translate words according to their own understandings, and in this way a new word often have many kinds of translations. This is also a reason why the translation of current political words is very chaotic at present. In recent years, there are very few books about the Chinese-English new words, the majority of which only compile the new words by categories and make simple explanations, so most of them are unable to be used in the actual translation work. Moreover, the theoretical studies on the Chinese-English new words are few at domestic, and the books and papers about this respect are extremely rare. This undoubtedly brings much inconvenience to the translators.

\section{B. Existing Questions}

The existed questions are misunderstanding, Chinese-type of English translations, and negligence of the cultural differences.

\section{Misunderstanding}

Accurate understanding of the original texts is the prerequisite for translation. Incorrect translations often appear because of the lack of accurate understanding of the connotation and extension of the original texts. For example, a phrase related to Taiwan problem such as “和平统一” is mistranslated as “peaceful unification”, which neglects the fact that Taiwan is one part of China. The correct translation should be “peaceful reunification”. Another example is “三角 债”, some translators mistakenly translate it as "triangle debts", such a translation only translate the literal meaning of the new word. This “三角债” actually refers to the problem of many companies delay each other's debts, thus should be translated as “debt chains”. Another example is “拳头产品”, which should be translated into "knock out product”.

2. Chinese-type of English translations

Some translators stuck to the original words too rigidly, taking it for granted to "take a seat according to ticket number" mechanically and literally. For instance, some people translate “豆腐渣”project as “bean curd residue project”, haven't transformed the vivid analogy of “豆腐渣”. The so-called “豆腐渣” project refers to architectural engineering built by cheats on labors and materials and of inferior quality. The word “豆腐渣” coincided with constitute equivalents with the English word "jerrybuilt". "Jerrybuilt" is a derogatory term in English, meaning "quickly and cheaply built without concern for quality”. Therefore, to translate “豆腐渣” project as “jerrybuilt project” can have effects of the equally good results from different methods.

3. Negligence of the cultural differences

"In terms of linguistics, languages are not only the reflections of cultures, but also the direct and effective tools to master one culture". (Chen Anding,1998: 269). The identical things or concepts have different connotations under different cultural backgrounds. Therefore, the translations of new words also need to consider the cultural particularities. For example, “四小龙” is translated as “the four dragons” in Asia. In the eastern countries, "dragon" symbolizes good luck and wealth, whereas in the Western culture, "dragon" is considered as a kind of horrible animals which symbolizes 
evil. Therefore, "the four dragons" is quite likely to bring bad imaginations to the westerners. The common translations are "the Four Tigers" or "the Asian Tigers", which borrow a lively and dynamic "tiger" in western culture to translate "dragon", the symbol of good luck and wealth in Chinese culture.

\section{TRANSLATION PRINCIPLES AND Methods}

The translation of the Chinese new words is an inseparable part of our country's image, therefore besides the analyses of translation theories, we should make researches on the translation principles and methods of Chinese current political new words to solve the practical problems.

\section{A. Translation Principles}

In terms of the translations of the current political new words, we should first pay attention to their faithfulness and expressiveness. Only when we understand their meanings can we grasp the intrinsic essences of the words and translate them accurately. For example, the original understanding of “小康” is "relatively comfortable", it seems too complex to use it in the translation of “全面建设小康社会”. Meanwhile, the original understanding is not right. “小康” was originally considered to be relatively well-off economic life, not having political or cultural meanings. Therefore, “全 面” should be understood as the whole country and translated into “across the country”. Actually, “全面建设小康社会” refers to a high level of well-off society involving over one billion people. Thus, the phrase should be translated as "build a well-off society in an all-round way". But in the translations of the documents of the Tenth National People's Congress second conference, the phrase was translated as "build a moderately prosperous society in all respects".

Terms of political affairs must be followed by development of the times, political, economic, cultural and many other areas at different periods of development and changes. Some terms as "Iron rice bowl" (the iron bow1), "four modernizations" (the Four modernizations), etc. possess a distinct expressive characteristics of the times, and have now been recognized, and as a fixed view and continue to be adopted. But relative to some of the terms update, such as: "carried forward"(carry forward our cause into the future), "through science and education" (national rejuvenation through science and education) and respond to and in accordance with the present trend of the times.

Then we should consider “elegance”, such as the translation of “以德治国，依法治国”.“法治” has the fixed phrase “rule of law”, however, there is no such a word“德治”in English. But in Chinese,“法治”和““德治”are on cross-references themselves. According to Nida's view, the translators should try to use an appropriate phrase to make“法治”and“德治”correspond to each other, thus achieving the aim of “reciprocity”. Therefore, this phrase can be translated into "We need to govern the country by combining the rule of law and the rule of virtue". By using the phrase of "rule of virtue", the entire English sentence not only achieves the goal of "expressing one's ideas", but also appropriates with the original texts very formally.

\section{B. Specific Methods}

In the translation practices, translators may adopt the following translation strategies to solve the practical problems, they are literal translation, free translation, transliteration, translation by restoring the borrowed words and borrowed corresponding English affixes.

1. Literal translation

Literal translation may be divided into three kinds of situations, complete literal translation, literal translation with explanation, and proper transformations of literal translation. As we all know, some of the political, economic, cultural and other aspects of terms or expressions are based on the condition of our country, which are unique in their meaning. Consequently, for the foreign readers who are lack of a certain background knowledge may find it difficult to understand. At this time, we need to take an explanatory translation. The 'three emphases education (the intensive education in the need to stress study, political awareness and integrity) (3 stresses education). In such process of translation, we must adopt the method of literal translation with footnotes, and then some explanation, make sure the vocabulary can explain the specific content of the implied terms and be translated clearly.

Firstly, complete literal translation. If there are equivalent words in English, it is better to make literal translation. We must select appropriate words and expressions according to the English customs to accurately transform those images which can be explained directly. For example, traditional Chinese families are families of several generations living together. Along with the changes of times, Chinese society has gradually formed a kind of core family-based structure. It seems a little bit of Chinglish if we only translate “大”“小” according to their Chinese meanings, that is to say, “big family” and “small family”. Other examples are“机构改革”(reform of the organizational structure) and“减轻农民负 担”(alleviate farmers' burden).

Secondly, literal translation with explanation. This approach has been recognized by the majority. It is generally agreed that in English there exist little words that are equivalent to the current political new words with Chinese characteristics. We adopt the method of literal translation with explanation could not only preserve the Chinese characteristics, but also make sure not to lose the accuracy. Such as "863" Plan, which is our country's high-tech research and development program. If we translate it into the "863" Program is too general, the foreign audience certainly could not understand. But if we translate it into "the March 1986 High-tech Program", the short explanation is 
simple and brief and may let the reader understand. Another example is“草根工业”, which should be translated into "grass root industry" (refers to village and township enterprises which take root among farmers and grow like wild grass). If we simply translate it as "grass root industry", it may cause a lot of confusions.

Thirdly, proper transformations of literal translation. The primitive images of the source texts cannot carry the same meaning in the target languages, and there are other images to express in the target languages, at this time we can use the method of proper transformations of literal translation to translate the figurative meanings. But attention should be paid to this kind of situations that both Chinese and English should have images, although the images are different, they can express similar meanings.

2. Free translation

Free translation may be divided into two kinds of situations, ordinary circumstances and the translation of fuzzy words.

First of all, ordinary circumstances. As a result of the Chinese inherent characteristics, some words do not exist in English at all. If we translate them literally, it will only cause wrong translations. Moreover, if the translations of the current political words are wrong, the images of Chinese policies will be damaged abroad, and the consequences will be inconceivable. Then we should drop their Chinese forms and make free translations. Such as the phrase“发展才是硬道 理”,“硬道理”is a word with Chinese characteristics. But in the foreigners' opinions, "reason” is not "hard”. It is better to translate it into "Development is the top priority". When we use "top priority” to express “硬道理”, although we can not express the metaphor in Chinese, the basic meaning has been expressed.

Then, the translation of the fuzzy words. Chinese traditional culture has fuzzy features, whereas the Western culture is precise. This is the natural result resulted from the self-intuitive thinking and logical thinking advocated by the Chinese and Western culture respectively. The fuzzy features are also manifested in the current political words. For example, “继续做好文化科技下乡, 扶贫工作”. Culture, science and technology are unable to go to the countryside, so we should clarify who are going to the countryside. Then the sentence should be translated as "We will work hard to bring culture, science and technology to the rural areas, continue aid-the-poor programs". In the translation of the fuzzy words, we should pay attention to reduce the traces of Chinglish and enhance the readability of the translation. Such as “一刀切”(impose uniformity on) refers to use one kind of routine to do any things. If we translate the phrase according to the literal meaning, then we may "kill people".

3. Transliteration

Some words, if translated by literal translation or free translation, would lead to the loss of some Chinese meanings. Some commonly used words can fully take the form of transliteration which not only manifest the Chinese culture, but also play the propaganda role. For example, China's giant pandas presented to Taiwan were named as“团团”“圆圆” and translated as “Tuantuan” and “Yuanyuan”.“福娃”, the mascots of the 2008 Beijing Olympic Games was firstly translated as "Friendliness". But the translation has suffered much controversy since its publication, and has been officially changed to "Fuwa". In fact, many Chinese pinyin words have already been incorporated into the English vocabulary, such as "wushu" "yinyang" and "fengshui".

4. Four-character combination of words and Translation

Four-character combination of phrases or idioms are more widely used in Chinese expression, and is a unique character of Chinese language. The form is simple, but is a welcome means of expression. And this four-character phrase, or idiom is characterized by the connotation of words which are not merely the meaning of their respective components of its meaning while it is often implied in the phrase being, therefore, in the process of translation they cannot be translated word for word. At the same time, when the Chinese proverbs are translated into English, it is not easy for the translator to maintain its original flavor, so the actual translation as far as possible to be translated in English with relative and other expressions. If it is not a perfect right to do so, then the translator have to follow the principle of faithfulness in order to convey the original meaning, thus avoiding the "Chinglish" phenomenon.

5. Translation by restoring the borrowed words

The external words have composed a part of Chinese new words. There is no doubt that when translating the borrowed words, we can also employ the method of restoring translation. Here restoring translation refers to return "the imported products” to the true themselves, such as “峰会” (summit conference) “克隆” (clone)“传销” (multi-level marketing) “生物恐怖主义”(bio-terrorism)“白皮书”(white paper) and so on. Another example is“第三产业”(tertiary industries). Some translators take for granted that it is a new Chinese phrase, and translate it as "the third industry". To avoid this kind of situation, the translators should read English newspapers and magazines frequently; in this way can we distinguish the borrowed words and make restoring translations.

6. Borrowed corresponding English affixes

Affixation is one kind of derivation methods, which constitutes new words by using the affixes in the grammatical form. As the prefixes and suffixes have strong expression power, when appropriately used might add much color to the translations of many new words that have no precedents to follow. Moreover, they can save a lot of space, which can be described as simple and expressive, twice the result with half the effort. For example, the English prefix " $\mathrm{N}$ " which stands for “nuclear”, is translated into“核”. Therefore, “核工厂”禁止使用核武器”should be translated into “N-plant”, "N-bans" respectively. The following are also some affixes contributing to the translations of Chinese new words. For 
example, “单”(single-;one-)“单亲家庭”(single-parent family),“单身母亲”(single mother); “防”(anti-;-proof; counter-; -resistant).

\section{CONCLUSION}

Language Translation aims to better serve the cross-cultural communication to help the Chinese (SL) people have their own unique things introduced to the English(TL) people. Translation of the political new words is to promote the spirit of innovation, not rigidly adhere to a fixed form, to follow a consistent trend of the times and development. Meanwhile, it is a good grasp with Chinese characteristics to avoid creating a puzzling "Chinglish" expression in order to promote communication in politics, economics, culture and other aspects with the western world, to enrich the connotation of the Chinese language as well as enhancing China's influence in the world, so that "China English" variant of the English language can be recognized and accepted worldwide. In short, the accurate and appropriate translations of current political new words may promote smooth progress of Chinese and foreign countries' exchanges, and let the whole world understand that China is very important. Based on the above researches, we have learned many useful methods of translating Chinese current political new words into English. Besides, to avoid the emergence of a variety of translation problems, translators should enhance their senses of responsibilities. At the same time, translators should strengthen their studies, understand and master the current political knowledge, improve their comprehensive qualities, earnestly study the solutions of the translation problems and heighten the capabilities of translating Chinese new words.

\section{REFERENCES}

[1] Chen anding.(1988).English-Chinese Contrast and Translation. Beijing: China Translation and Publishing Corporation.

[2] Gerard M. Dalgish. (1972). Random House Webster's Dictionary of American English. Beijing: Foreign Language Teaching and Research Press.

[3] Jack Richard. (1985). Dictionary of Applied Linguistics. Pearson ESL.

[4] Liu biqing. (1992). Chinese-English Contrast and Translation. Nan chang: Jiangxi Education Press.

[5] Liu fagong. (2002) On The Principles Of Business Chinese-English Translation. Chinese Translators Journal.1, 44-48

[6] Lu guoqiang. (1983).Modern English Lexicology. Shanghai: Shanghai Foreign Language Education Press.

[7] Wang xiangbing. (2002). On The Translation Of Chinese Cultural Words Of Chinese Reports in Time Magazine. Shanghai Journal of Translators for Science And Technology.2, 19-22

[8] Wu weixiong (1998).On The Translation Of Chinese Slogans. Chinese Translators Journal.1, 35-38

Jingjing Cui was born in Dezhou, Shandong, China in 1977. She received her M.A. degree in linguistics from School of foreign languages in Shandong University, China, in 2007. She is currently a lecturer in the department of Foreign Languages in Dezhou University, Dezhou, China. Her research interests include language teaching and translation. 